\title{
Organizational and Occupational Culture and the Perception of Managerial Accounting Terms: An Exploratory Study Using Perceptual Mapping Techniques
}

\author{
Steven D Johnson \\ Utah Valley State College \\ E-Mail: johnsosd@uvsc.edu \\ Hian Chye Koh \\ SIM University \\ E-Mail: hckoh@unisim.edu.sg \\ Larry N Killough \\ Virginia Tech \\ E-Mail: larry@vt.edu
}

\begin{abstract}
Organizational culture and occupational culture are powerful forces that drive organizations and their members. This study explores their effects on the perception of managerial accounting terms, as measured by semantic differential scales. The sample comprises two occupational groups (i.e. 64 management accountants and 68 non-financial managers) in ten organizations. Organizational culture is measured by the Organizational Culture Inventory. INDSCAL and cluster analysis results indicate that different organizational and occupational cultures are associated with differential perceptions of managerial accounting terms. This finding has implications on the effectiveness of accounting communication. It also shows the importance of understanding the effects of organizational culture and occupational culture, which are powerful forces driving organizations and their members.
\end{abstract}

Keywords: Organizational Culture, Occupational Culture, Accounting Communication, Managerial Accounting Terms, Perceptual Mapping Techniques 


\section{INTRODUCTION}

That cultures and subcultures exist in organizations and/or their sub-units is well documented in the literature (see, for example, Lewis (1996) and Hofstede (1998a)). Culture can generally be thought of as the values shared by members of a group (be it a community, organization or sub-unit) that manifest themselves in the practices of that group. Hence, culture can be associated with a nation, region, corporation, department, function or any form of grouping (e.g., a profession or an occupation).

This study looks at the effects of organizational and occupational culture in a managerial accounting context. In particular, the research framework focuses on accounting as a language for communication. As aptly summarized by Lewis (1985), the communication process begins with a sender having a message to be communicated to the receiver. The sender encodes his thoughts into a message and the receiver decodes the message into thoughts. It is this process of encoding and decoding messages that can lead to failure because the sender (receiver) encodes (decodes) messages by using a filter that is molded by his background (which is affected by accumulated past experiences, education, environment, prejudices, social values, beliefs, etc.). More specifically, differences in linguistic filters can lead to different worldviews so that the meanings embodied in equivalent words can have quite different meanings in different groups (Sherblom, 1998).

Organizational and occupational culture is an important source of background differences that can lead to differences in vocabularies, understanding of basic concepts, attitude towards accounting, and the consequent failure in accounting communication. This study explores the effects of organizational and occupational culture on the perception (or rather differential perceptions) of managerial accounting terms. It also attempts to explore what the differential perceptions (if any) are and how they are linked to respondents' backgrounds in terms of their organizational and occupational culture.

The study is expected to increase the current understanding of organizational and occupational culture and accounting communication. It can also identify potential determinants of accounting communication failure and help suggest ways to improve accounting communication.

\section{LITERATURE REVIEW}

Culture can be thought of as a set of cognitions shared by members of a social unit that are acquired through social learning and socialization processes (Cooke and Rousseau, 1988). Over time, past experiences are used as a basis for determining action and these interactions become shared knowledge. This shared knowledge is 
then used by organizational members to interpret past experiences and current situations and to guide present and future actions (Bloor and Dawson, 1994). This evolution of events forms the basis of organizational culture. Organizational members, however, may simultaneously hold membership within a number of cultures (e.g., professional or other affiliations and distinct work and social groups in an organization).

\section{Organizational and Occupational Culture}

Several definitions of organizational culture exist, including Hofstede's (1991) definition of it as the collective programming of the mind which distinguishes the members of one organization from another. More generally, organizational culture can be defined in terms of values shared by members of an organization (or its subunit) that manifest themselves in the practices of that organization or sub-unit. Pratt et al. (1992) found that organization culture is a function of size, technology, structure and functional area. Yaakov (1996) suggested that organizational culture is affected by the nature of the industry the organization operates in. Other factors that influence organizational culture include national culture (Pratt et al., 1992), societal culture (Bloor and Dawson, 1994), and organizational environments and goals (Cooke and Rousseau, 1988).

Prior research has measured organizational culture among various dimensions. For example, Kilman and Saxton (1983) classified organizational culture along the dimensions of technical/human concern and short-/long-term orientation while Cooke and Rousseau (1988) classified it along the dimensions of task/security, satisfaction culture and people/security. Hofstede et al. (1990) reported the following six dimensions of organizational culture: process-/results-oriented, employee-/joboriented, parochial/professional, open/closed system, loose/tight control and normative/pragmatic.

Smircich (1983) suggested a cultural view of organizations in which a dominant culture shapes the meaning of significant symbols in the organizations. In addition, Ott (1989) reported that organizations could have subcultures that interlock, overlap, partially coincide and sometimes conflict with the organizations' dominant culture. This study focuses on both organizational culture and occupational culture. Both can play an important role in the accounting communication process.

In the study, management accountants comprise one of two primary groups of respondents. They can be thought of as a more restricted version of occupational culture. In particular, management accountants undergo similar education and 
training, and perform similar work. These experiences mold perceptions. Consequently, it can be expected that management accountants hold similar and precise views about managerial accounting terms. In addition, members of the same profession are likely to have similar interests, values and attitudes, which can also mold perceptions. More importantly, professional affiliations can create different linguistic repertoires or codes for intra-group communications and/or inter-group communications (Belkaoui, 1980). The existence of a management accounting culture is reported by Granlund and Lukka (1998). More generally, Hofstede (1998b) found the existence of a professional culture in organizations.

As compared to professional culture, occupational culture is a broader construct. It is believed to be the result of similar occupational backgrounds and experiences of different groups of organizational members. In particular, occupational culture (or subculture) develops through social interaction, shared experience, common training and affiliation, mutual support, associated values and norms, and similar personal characteristics of members of a particular occupational group. Like organizational culture, occupational culture develops distinct jargon and shapes perceptions of reality by developing classification systems to describe experiences and concepts (Hansen, 1995). More generally, all cultures operate from cognitive models to filter expectations - a kind of meaning-making (Hansen and Kahnweiler, 1997).

Schein (1996) identified three broad occupational cultures in organizations: (1) the "operators" occupational culture that applies to line managers and workers who make and deliver the products and services that fulfill the organization's basic mission, (2) the "engineers" occupational culture that applies to technocrats and core designers in any functional group (e.g., accountants, software programmers, market researchers, etc.), and (3) the "executives" culture that applies to top managers and executives. Hansen and Kahnweiler (1997) provided evidence for the existence of the “executives” culture. In addition, Jackall (1988) provided evidence of an occupational culture for managers who are not executives. Further, Malmi (1997) reported the existence of the "engineers" culture and von Meier (1999) found the existence of “operators” and “engineers” cultures.

Different occupational cultures are expected to both interact and conflict (see, for example, Malmi (1997) and von Meier (1999)). Organizational culture and occupational culture can also influence each other through the processes of selection and socialization. For example, accountants who are comfortable with a particular organizational culture may self-select into that organization. This process of selection (i.e. recruitment and self-selection) therefore brings about a partial merging of 
occupational/professional and organizational cultures. Socialization refers to the process by which the culture values of organizational members are brought into line with the organizational culture (e.g., through common values and goals, rituals and procedures, training, evaluation and reward systems, etc. (Hofstede et al., 1990)). However, occupational/professional culture is still expected to persist in organizations because of occupational/professional affiliations.

Finally, it is believed that occupational culture may have greater influence over work styles and perspectives than an organization's procedures and polices (part of organizational culture - Dellana and Hauser (1999)). Also, occupational culture crosses organizational boundaries and is often imported (Hansen, 1995).

\section{Accounting Communication}

Without effective communication, even the most sophisticated accounting information will not generate the appropriate decision and action (Parker et al., 1989). As Goldberg (1965) had noted several decades ago, communication is the pivotal problem in accounting and very few accounting terms and expressions can be used unconditionally without some risk of their being misinterpreted. Effective communication implies that for any particular word/term, the name (denotative meaning) and the interpretation (connotative meaning) are similar for the individuals involved in the communication process.

Haried's (1972; 1973) research (the first published work in accounting communication) focused on the meaning of accounting terms as a core component of accounting communication. He attempted to measure the connotative meaning (i.e. perception) of selected financial accounting terms. Using a semantic differential approach, he found no significant differences in the meaning of commonly used accounting terms between preparers and users of financial statements. Houghton's (1988) re-examination of Haried's data, however, found significant differences in the connotative meaning of accounting terms.

Belkaoui (1980) found with respect to the use of the accounting language that academicians used a formal language, professional accountants used a public language, and students used a combination of both. He concluded that the perception of accounting terms vary in the manner with which they can be recognized, grasped or understood by different professional groups. In a later study, Monti-Belkaoui and Belkaoui (1983) concluded that "language differences result ... in specific perceptual differences in understanding the same concept used within disciplines, industries and professions” (p. 124). Adelberg and Farrelly (1989) also found significant 
differences in the connotative meaning between accountants and users because of differences in professional affiliations.

Haried (1973) and Houghton (1988) found possible effects of differential levels of education on the development of meaning, and Houghton (1987) suggested that meaning changes as a result of more experience and education. That latter also concluded that the cognitive structure of experts (i.e. accountants) is richer and more differentiated than that cognitive structure of novices (i.e. users). Finally, Johnson et al. (1999) examined the meaning of managerial accounting terms and reported differential perceptions across organizations.

\section{Organizational and Occupational Culture and Accounting Communication}

Perceptions of accounting terms are molded by the backgrounds of the sender and receiver of messages in the communication process. The most fundamental principle of perception that has been consistently highlighted in the literature is that it differs across individuals or groups of individuals for the same object, symbol, event or person (Gibson et al., 1994). This can be explained by the fact that perception is influenced by a host of factors (e.g., experience, educational background, work context and job function, needs and motivation, group membership, etc.). To the extent that the levels of these factors vary across different individuals/groups, perceptions can differ (Dessler, 1984). This study looks at the different factors collectively as organizational culture and occupational culture. As Sherblom (1998) stated, encoding and decoding in the communication process involve groups and their multiple cultural influences.

For occupational culture, the study examines management accountants and nonfinancial managers as two separate groups with different cultures. It can be noted that management accountants besides belonging to the accounting profession (and hence the accounting culture) also fall into the "engineering" occupational culture discussed earlier. On the other hand, non-financial managers fall into the "operators" occupational culture (or even a "managers" culture as proposed by Jackall (1988)). Essentially, organizational members belonging to a defined group are expected to possess an occupational culture and members belonging to a particular organization are expected to possess an organizational culture. These cultures, in turn, are expected to affect the perception of managerial accounting terms. 


\section{RESEARCH METHODOLOGY}

The twofold objectives of this study can be stated as follows. Firstly, the study investigates if differences in organizational culture and occupational culture are associated with differences in the perception of managerial accounting terms. Secondly, if significant differences in perception are found, it further explores what the differential perceptions are and how they relate to the respondents' organizational and occupational culture. The research methodology employed in the study is summarized below.

\section{Research Framework and Research Questions}

Given the objectives of the study and the existing literature, the research questions addressed in the study can be expressed as follows:

$Q_{1}$ : Is organizational culture associated with any differential perceptions of managerial accounting terms?

$Q_{2}$ : Is occupational culture associated with any differential perceptions of managerial accounting terms?

$Q_{3}$ : If organizational and/or occupational culture are/is associated with differential perceptions of managerial accounting terms, how are the perceptions different?

$Q_{4}$ : Further, what are the possible explanations for the relationships between organizational and occupational culture and the differential perceptions of managerial accounting terms?

It is expected that organizational and occupational culture impact on the perception of managerial accounting terms. For example, management accountants' perception of "budget" may be more related to the administrative aspects whereas non-financial managers' perception of "budget” may be more related to its use (say, in planning, control or performance evaluation). Similarly, given that organizations with different characteristics may use the "budget" differently (Poon and Koh, 1995), organizations with different culture are likely to have different perceptions of the "budget”.

For occupational culture, as mentioned earlier, two groups are examined in the study - namely, management accountants and non-financial managers. As for organizational culture, the organizations participating in the study are assessed by the Organizational Culture Inventory or OCI (Cooke and Lafferty, 1984 and 1987) and clustered into groups of similar organizational culture. Nine selected managerial accounting terms are used in the study. 


\section{Data Collection and Sample Selection}

Data were collected via self-administered questionnaires sent to management accountants and non-financial managers in ten organizations. Initially, a list of 32 diverse organizations stratified by the standard industry code (SIC) within manufacturing was selected from the Southeast United States. Four additional organizations identified by Howell and Soucy (1987) as representative of the new "world class" manufacturing philosophy were also included. To ensure sufficient management accountants and non-financial managers within each selected organization, only organizations that employed more than 1,000 employees were included in the list. The 36 organizations were then contacted to solicit their participation in the study. Ten organizations agreed to participate.

\section{Instrument Development}

The meaning of managerial accounting terms was measured using a semantic differential instrument. A process similar to that used by Haried (1972) was used. In particular, thirty-six managerial accounting terms representing a board range of topics were selected for an initial survey instrument, which was sent to the controller and manufacturing manager of 200 large, publicly held firms. The subjects were asked to identify important and regularly used terms. Based on 108 responses, 12 managerial accounting terms were selected for an intermediate survey instrument.

Concurrently with the above, bipolar adjective scales that are relevant to managerial accounting were developed using a triad procedure comprising 38 graduate students at a large US university (15 in accounting, 16 in management and 7 in industrial engineering). The 36 resulting bipolar adjective scales were matched with each of the 12 selected managerial accounting terms in the intermediate survey instrument. This instrument was sent to the same sample of controllers and manufacturing managers. They were requested to assess the 12 managerial accounting terms on the basis of the 36 bipolar adjective scales.

Based on principal component analysis results of 79 responses and the judgment of the researchers, the following nine managerial accounting terms were selected for the study: (1) budget, (2) production cost, (3) fixed cost, (4) direct cost, (5) return on investment, (6) variance, (7) contribution margin, (8) just-in-time, and (9) variable cost. Further, the following 12 bipolar adjective scales (7-point) were used: (1) important: unimportant, (2) variable: fixed, (3) irrelevant: relevant, (4) measurable: unmeasurable, (5) temporary: permanent, (6) cost-oriented: revenue-oriented, (7) 
uninformative: informative, (8) operational: strategic, (9) necessary: unnecessary, (10) dynamic: static, (11) adverse: beneficial, and (12) controllable: noncontrollable.

Occupational culture was measured by categorizing the respondents as management accountants or non-financial managers (as a dummy variable). As members of the same occupational/professional group respectively, accountants and non-financial managers are expected to have their own respective culture (i.e. similar frame of reference, shared values, experiences, etc). Prior research studies have documented a strong occupational culture among accountants (see, for example, Bayou (1993)), including that among management accountants. Although nonfinancial managers are a more general group, prior research studies have also documented a strong occupational culture among managers (see, for example, von Meier (1999)).

Organizational culture was measured in the study by the Organizational Culture Inventory or OCI (Cooke and Lafferty, 1984 and 1987). Cooke and Rousseau (1988) reported that OCI is a widely used instrument with a very high degree of reliability and validity. Also, in a study of four instruments commonly used to measure organizational culture, Xenikou and Furnham (1996) found that the OCI had the best internal reliability and validity and recommended it over the others. OCI was designed to measure the direction and intensity of the shared norms and expectations that guide the thinking and behavior of organizational members in relation to both their tasks and to other people. The instrument uses a 5-point scale to measure 12 cultural styles, which can be further classified as task/security culture, satisfaction culture and people/security culture (Cooke and Rousseau, 1988). For the study, instead of ten items for each cultural style (as in the original OCI), only two items were used. This reduced significantly the task that the respondents had to undertake and was expected to enhance the response rate.

To categorize the ten participant organizations into organizational culture groups, scores from the 12 OCI cultural styles were subject to principal component analysis. Based on the cultural styles with the highest loading on each of the three resulting components, cluster analysis was performed to group the ten organizations into groups of similar organizational culture. Three separate clusters of sufficiently distinct organizational culture were identified: (1) people-oriented/humanistic organizational culture [six organizations]; (2) task-oriented/cooperative organizational culture [three organizations]; and (3) conventional/bureaucratic organizational culture [one organization - a shipbuilding and repair firm]. As in the case of occupational culture, a categorical variable is used to represent organizational culture. 


\section{Statistical Methods}

To examine the research questions of interest, perceptual mapping techniques were used. Such techniques are appropriate for the exploratory study of perceptions and have been used in prior research to study differential perceptions of financial accounting terms (e.g., Adelberg and Farrelly, 1989) and auditing terms (e.g., Low and Koh, 1997). In particular, individual differences scaling analysis (INDSCAL), a multidimensional scaling (MDS) technique, was used (see Carroll and Chang, 1970). INDSCAL results can show whether the perceptions of managerial accounting terms differ by organizational culture (i.e. people-oriented/humanistic versus taskoriented/cooperative versus conventional/bureaucratic) and/or by professional culture (i.e. management accountants versus non-financial managers). Also, if differential perceptions are indicated, INDSCAL results show how the perceptions differ. In addition, the results can identify the common perceptual map underlying the different groups, if any exists. Generally, terms that are close together on the perceptual map are perceived to be similar by the respondents and terms that are far apart on the perceptual map are perceived to be dissimilar by the respondents. The dimensions of the perceptual map indicate the cognitive structure that the respondents used to perceive the terms.

Data input to the INDSCAL procedure comprised distance matrices among the nine managerial accounting terms selected for the study. These were computed as Euclidean distances, using the 12 bipolar adjective scales. The following distance matrices were computed: (1) three for organizational culture, and (2) two for occupational culture. Finally, cluster analysis was performed on the INDSCAL outputs to help interpret the results. In particular, the cluster membership indicates which managerial accounting terms are perceived similarly and which are perceived differently.

The SPSS (Statistical Package for Social Science) software was used to perform all the statistical analyses in the paper.

\section{RESULTS AND IMPLICATIONS}

The distribution of respondents across organizational culture and occupational culture is given in Table 1. As can be seen, there are a total of 132 respondents, of which 64 are management accountants and 68 are non-financial managers. Further, out of the 132 respondents, 84 are in organizations with people-oriented/humanistic culture, 28 are in organizations with task-oriented/cooperative culture and 20 are in a shipbuilding and repair firm with conventional/bureaucratic culture. 
Table 1 Distribution of Respondents by Organizational Culture and Occupuptaional Culture

\begin{tabular}{lccc}
\hline & $\begin{array}{c}\text { Management } \\
\text { accountants }\end{array}$ & $\begin{array}{c}\text { Non-financial } \\
\text { managers }\end{array}$ & Total \\
\hline People-oriented/ & 40 & 44 & 84 \\
Humanistic Culture & 4 & 4 & 8 \\
Organization A: & 7 & 9 & 16 \\
Organization B: & 5 & 5 & 10 \\
Organization C: & 7 & 10 & 17 \\
Organization D: & 11 & 10 & 21 \\
Organization E: & 6 & 6 & 12 \\
Organization F: & & & \\
& 14 & 14 & 28 \\
$\quad$ Task-oriented/ & 5 & 5 & 10 \\
Cooperative Culture & 4 & 4 & 8 \\
Organization G: & 5 & 5 & 10 \\
Organization H: & & & 20 \\
Organization I: & 10 & 10 & 132 \\
Conventional/ & 10 & 10 & \\
Bureaucratic Culture & 64 & 68 & 20 \\
Organization J: & & & \\
TOTAL & & &
\end{tabular}

\section{Organizational Culture and Perception of Managerial Accounting Terms}

Based on the assessment of the nine managerial accounting terms on the basis of the 12 bipolar adjective scales, a distance matrix (comprising Euclidean distances for the nine terms) was computed respectively for each of the three clusters of organizations with different organizational culture (i.e. people-oriented/humanistic, task-oriented/cooperative and conventional/bureaucratic). INDSCAL was then performed on the three resulting distance matrices. The results are summarized in Table 2.

As can be seen from Table 2, the INDSCAL results indicate a Stress index of 0.1276 and R-square of $89.71 \%$. These results are deemed sufficiently good fitting for the purpose of the study. The INDSCAL results also indicate a common perceptual map of the perceptions of the nine managerial accounting terms for the three different organizational culture groups (see the coordinates on the three dimensions in Table 2). The individual group perceptual maps (for each organizational culture) can be derived 
by multiplying the common perceptual map coordinates by the square roots of the respective weights for the three organizational culture groups. To analyze the INDSCAL results further, the perceptual maps for the people-oriented/humanistic, task-oriented/cooperative and conventional/bureaucratic organizational culture organizations are plotted in Figure 1. The results of cluster analysis are also incorporated in Figure 1 by drawing the boundaries of the different clusters of similarly perceived terms. That is, terms belonging to the same clusters are perceived to be similar and terms belonging to different clusters are perceived to be different by the respondents.

A noticeable difference between the perceptions of the peopleoriented/humanistic and task-oriented/cooperative cultures on one hand and the conventional/bureaucratic culture on the other is that the former perceive the nine managerial accounting terms mainly on dimensions 1 and 2 whereas the latter perceive the terms mainly on dimensions 1 and 3 (see the weights in Table 3). As can be seen on Figure 1, the perceptual maps for the people-oriented/humanistic culture and task-oriented/cooperative culture are very similar (in fact, identical with respect to the relative positions of managerial accounting terms). This finding is consistent with the explanation that both the cultures are similar in terms of their emphasis on satisfaction (i.e. people-oriented for one and cooperation to complete the task for the other).

Another difference that can be noted from Figure 1 is the relative position (and cluster membership) of the terms as perceived by the conventional/bureaucratic culture vis-à-vis the other two cultures. The differences are shown more clearly in the two-dimensional diagrams (as well as the cluster membership of terms). In particular, the conventional/bureaucratic firm perceives fixed cost to be very different from all other terms (hence, it forms its own cluster).

It can also be noted that membership of the remaining clusters are rather different. More importantly, comparing the relative position of terms on the other important dimension (i.e. dimension 2 for the satisfaction culture [namely, the peopleoriented/humanistic culture and task-oriented/cooperative culture] and dimension 3 for the conventional/bureaucratic culture), just-in-time takes on special prominence for the latter whereas return on investment takes on special prominence for the other organizations. This explanation is consistent with Chatman and Jehn (1988), who conceptualized and found empirically that industrial characteristics have a direct and significant influence on organizational culture. 
Table 2 INDSCAL Results for Organizational Culture

\begin{tabular}{|c|c|c|c|c|c|c|c|c|}
\hline \multicolumn{9}{|c|}{ A. Common perceptual map } \\
\hline \multicolumn{3}{|c|}{ Managerial accounting term } & \multicolumn{2}{|c|}{ Dimension 1} & \multicolumn{2}{|c|}{ Dimension2 } & \multicolumn{2}{|c|}{ Dimension 3} \\
\hline \multicolumn{3}{|c|}{ Budget (BGT) } & \multicolumn{2}{|r|}{1.05} & \multicolumn{2}{|r|}{0.94} & \multicolumn{2}{|c|}{-0.76} \\
\hline \multicolumn{3}{|c|}{ Product cost (PCT) } & \multicolumn{2}{|r|}{.31} & \multicolumn{2}{|r|}{-0.50} & \multicolumn{2}{|c|}{-1.42} \\
\hline \multicolumn{3}{|c|}{ Fixed cost (FCT) } & \multicolumn{2}{|r|}{2.22} & \multicolumn{2}{|r|}{0.74} & \multicolumn{2}{|c|}{0.29} \\
\hline \multicolumn{3}{|c|}{ Direct cost (DCT) } & \multicolumn{2}{|r|}{0.07} & \multicolumn{2}{|r|}{-1.21} & \multicolumn{2}{|c|}{-0.77} \\
\hline \multicolumn{3}{|c|}{ Return on investment (ROI) } & \multicolumn{2}{|r|}{-0.77} & \multicolumn{2}{|r|}{1.67} & \multicolumn{2}{|c|}{-0.90} \\
\hline \multicolumn{3}{|c|}{ Variance (VAR) } & \multicolumn{2}{|r|}{-1.02} & \multicolumn{2}{|r|}{-0.73} & \multicolumn{2}{|r|}{0.45} \\
\hline \multicolumn{3}{|c|}{ Contribution margin (CMG) } & \multicolumn{2}{|r|}{-0.68} & \multicolumn{2}{|r|}{0.54} & & 1.37 \\
\hline Just-in & time (JIT) & & & -0.40 & & 0.04 & & 1.68 \\
\hline Variab & e cost $(\mathrm{V}$ & & & -0.78 & & -1.50 & & 0.07 \\
\hline Stress & $=0.1276$ & R-square & 0.8971 & & & & & \\
\hline B. Indivic & ıal group & erceptual & maps & & & & & \\
\hline Organ & ational $\mathrm{Cl}$ & lture & & & & Veights: & & \\
\hline & & & Din & Iension 1 & Dim & nension 2 & Dime & nsion 3 \\
\hline People & oriented/1 & umanistic & & 0.87 & & 0.38 & & 08 \\
\hline Task-c & iented/Cc & perative & & 0.78 & & 0.58 & & 03 \\
\hline Conve & tional/Bu & eaucratic & & 0.79 & & 0.15 & & 44 \\
\hline C. Cluste & members & & & & & & & \\
\hline People- & iented/Hu & manistic & Task-o & iented/Coc & perative & Conven & ional/Bure & aucratic \\
\hline Cluster1 & Cluster2 & Cluster3 & Cluster1 & Cluster2 & Cluster3 & Cluster1 & Cluster2 & Cluster3 \\
\hline BGT & DCT & $\mathrm{CMG}$ & BGT & DCT & $\mathrm{CMG}$ & FCT & DCT & CMG \\
\hline FCT & PCT & ROI & FCT & PCT & ROI & & PCT & VCT \\
\hline & VCT & JIT & & VCT & JIT & & ROI & VAR \\
\hline & VAR & & & VAR & & & BGT & JIT \\
\hline
\end{tabular}


A. People-oriented/Humanistic culture

1. Three-dimensional map

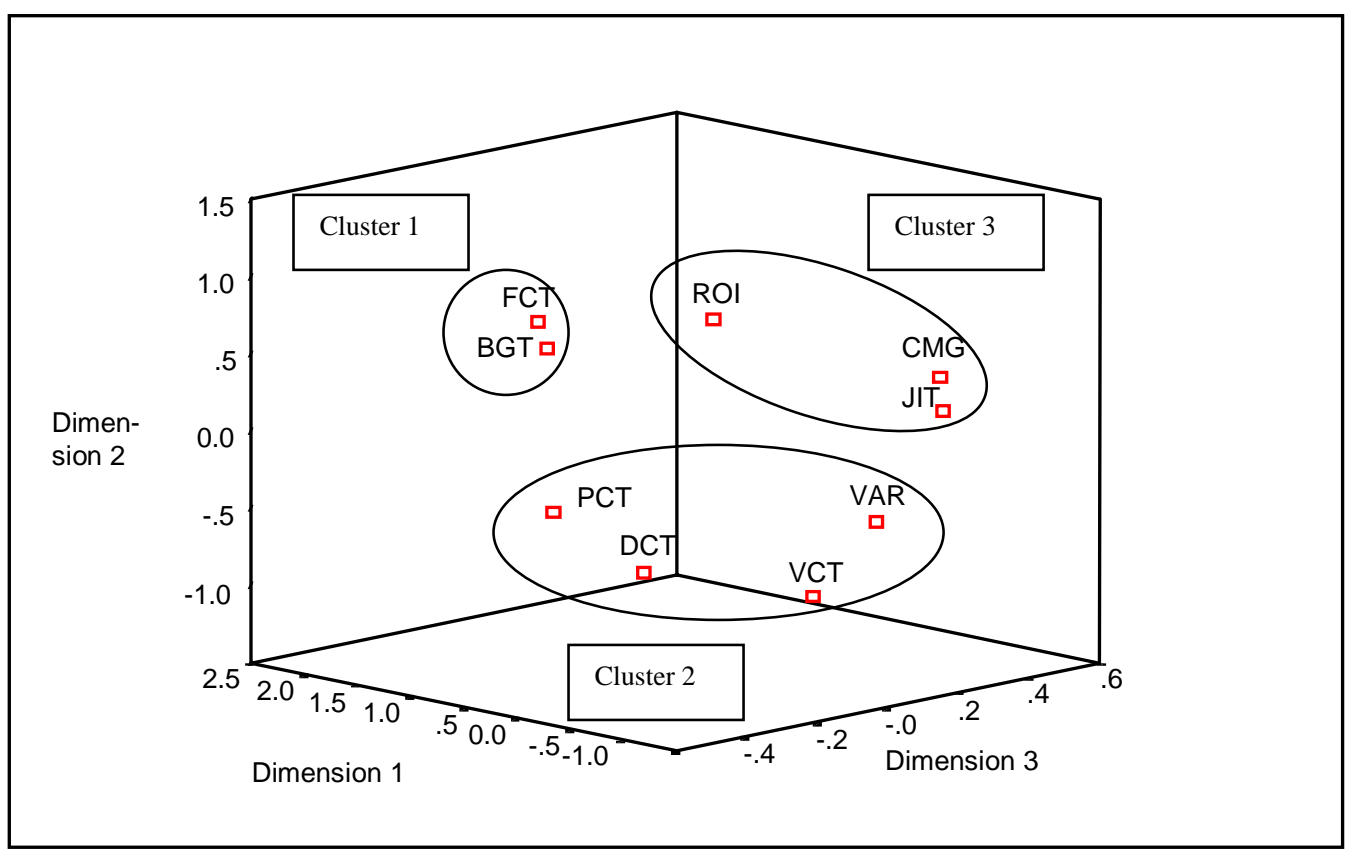

2. Two-dimensional map

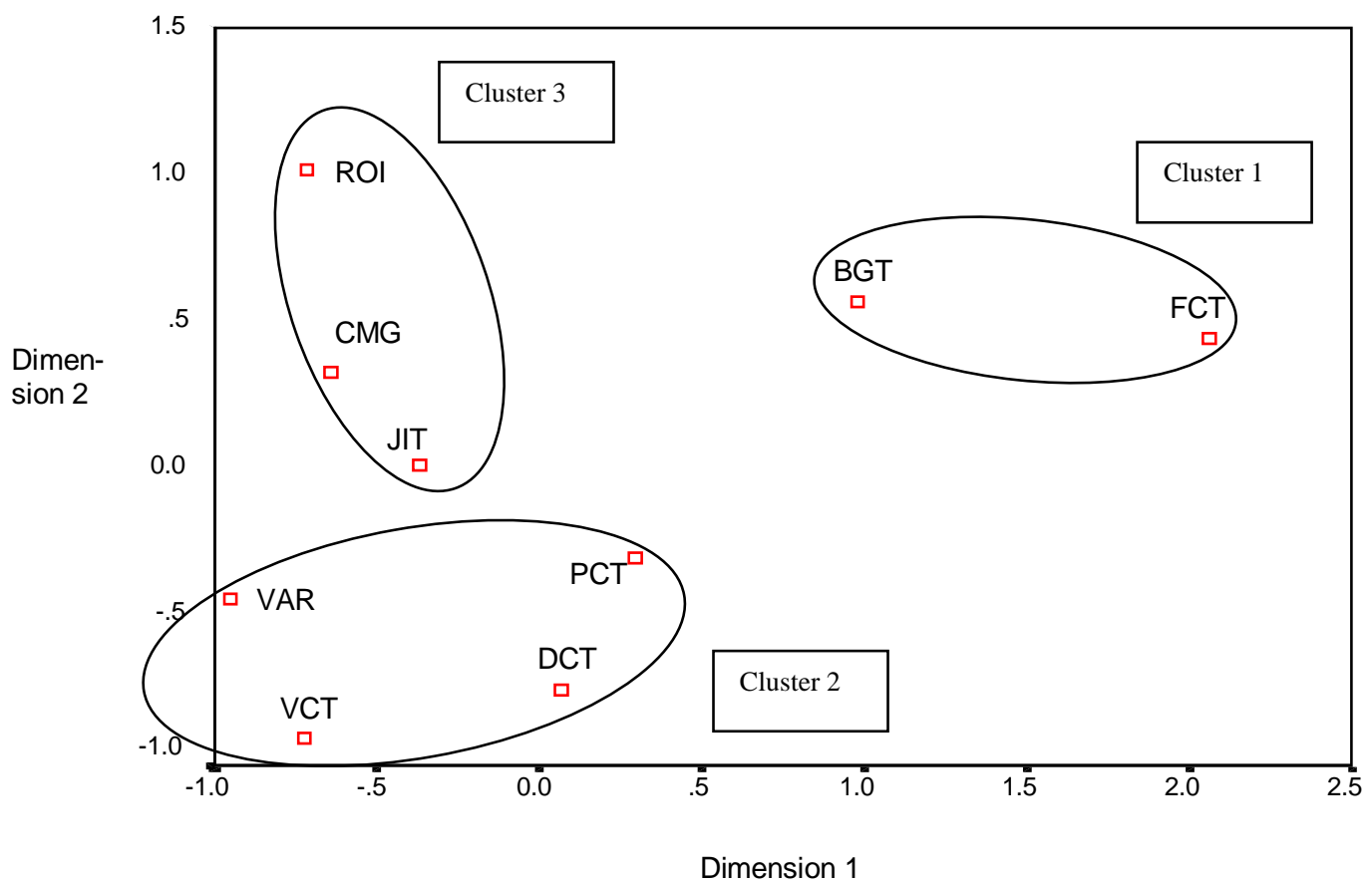

Figure 1 Perceptual Maps for Organizational Culture 
B. Task-oriented/Cooperative culture

1. Three-dimensional map

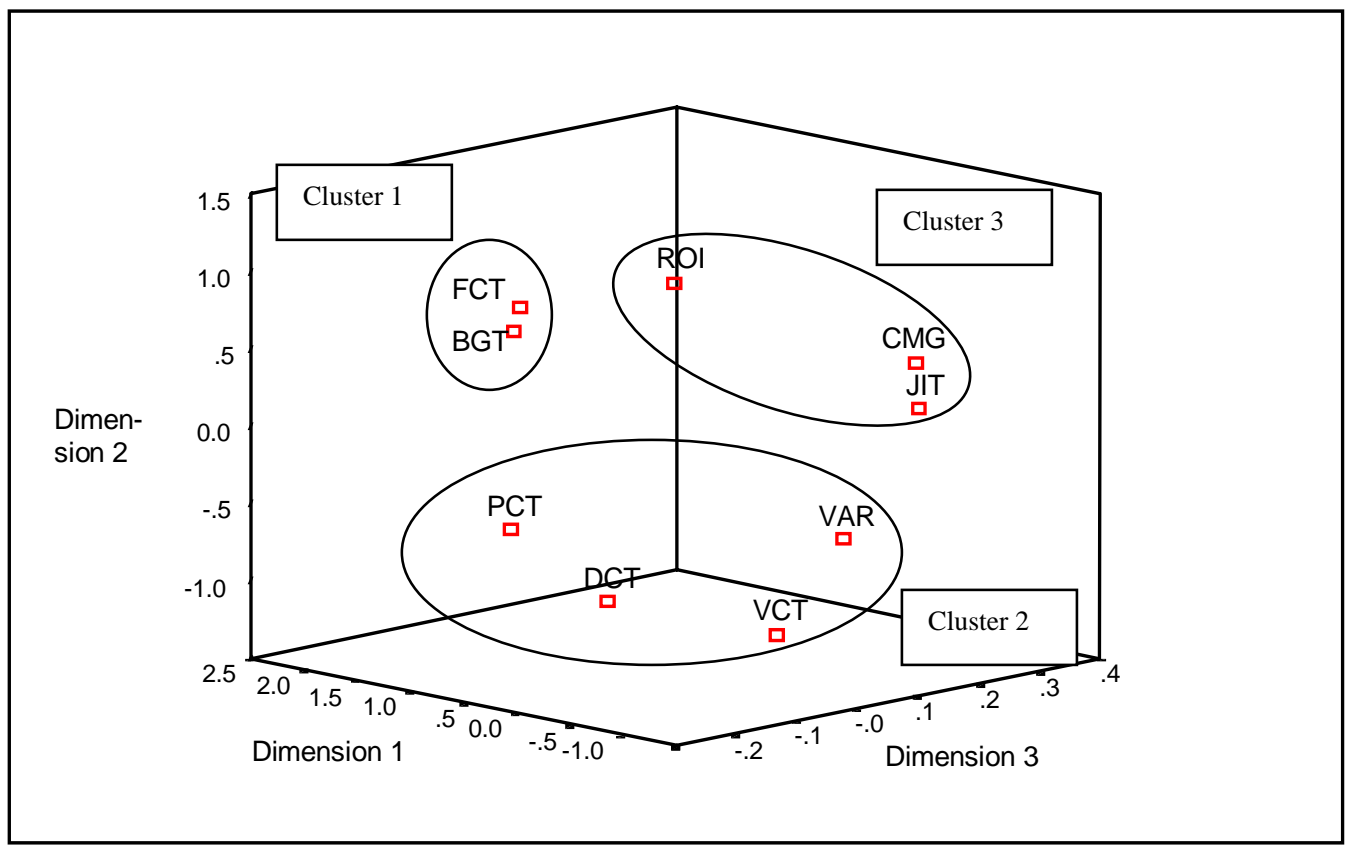

2. Two-dimensional map

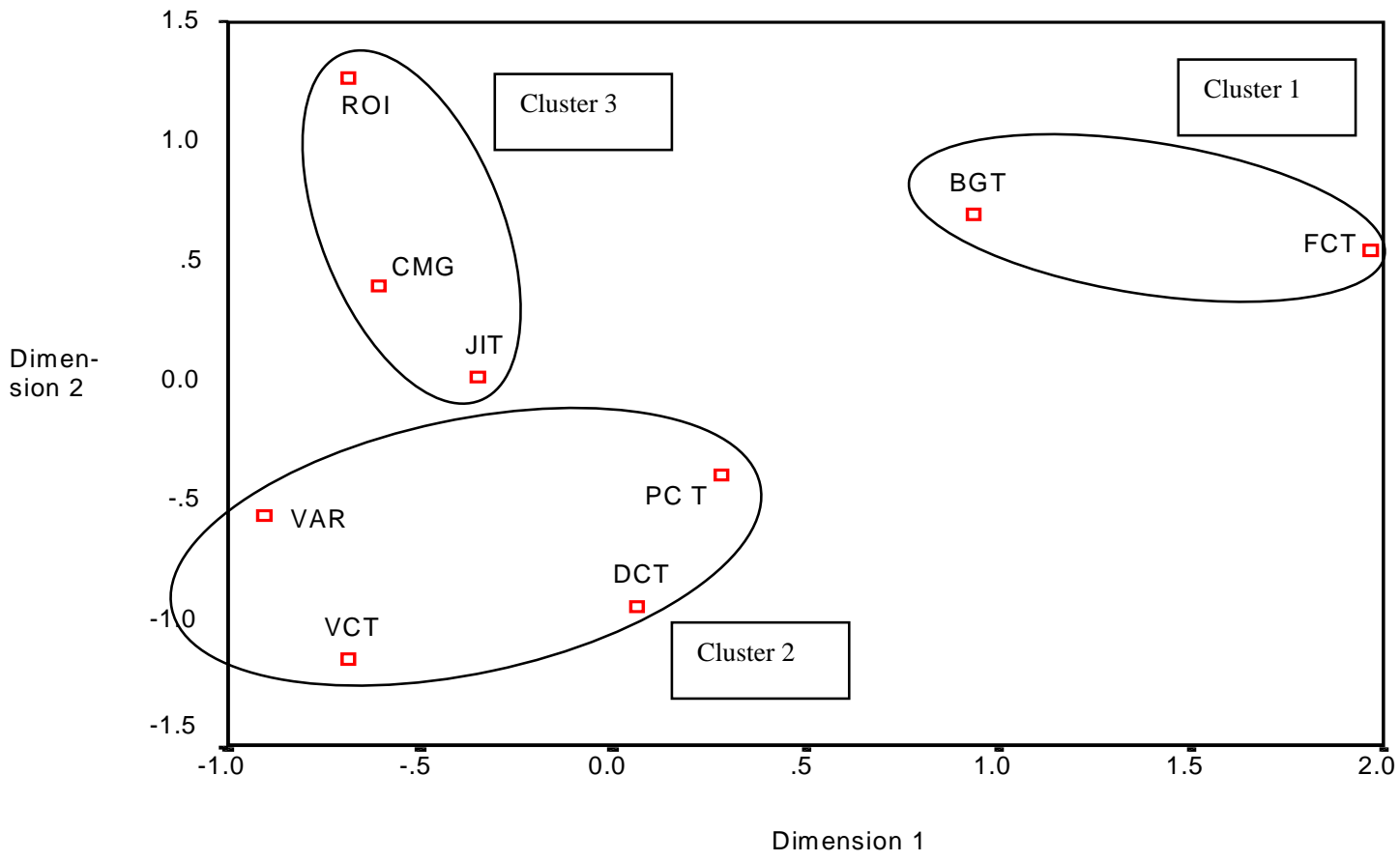

Figure 1 Perceptual Maps for Organizational Culture (continued) 
C. Conventional/Bureaucratic culture

1. Three-dimensional map

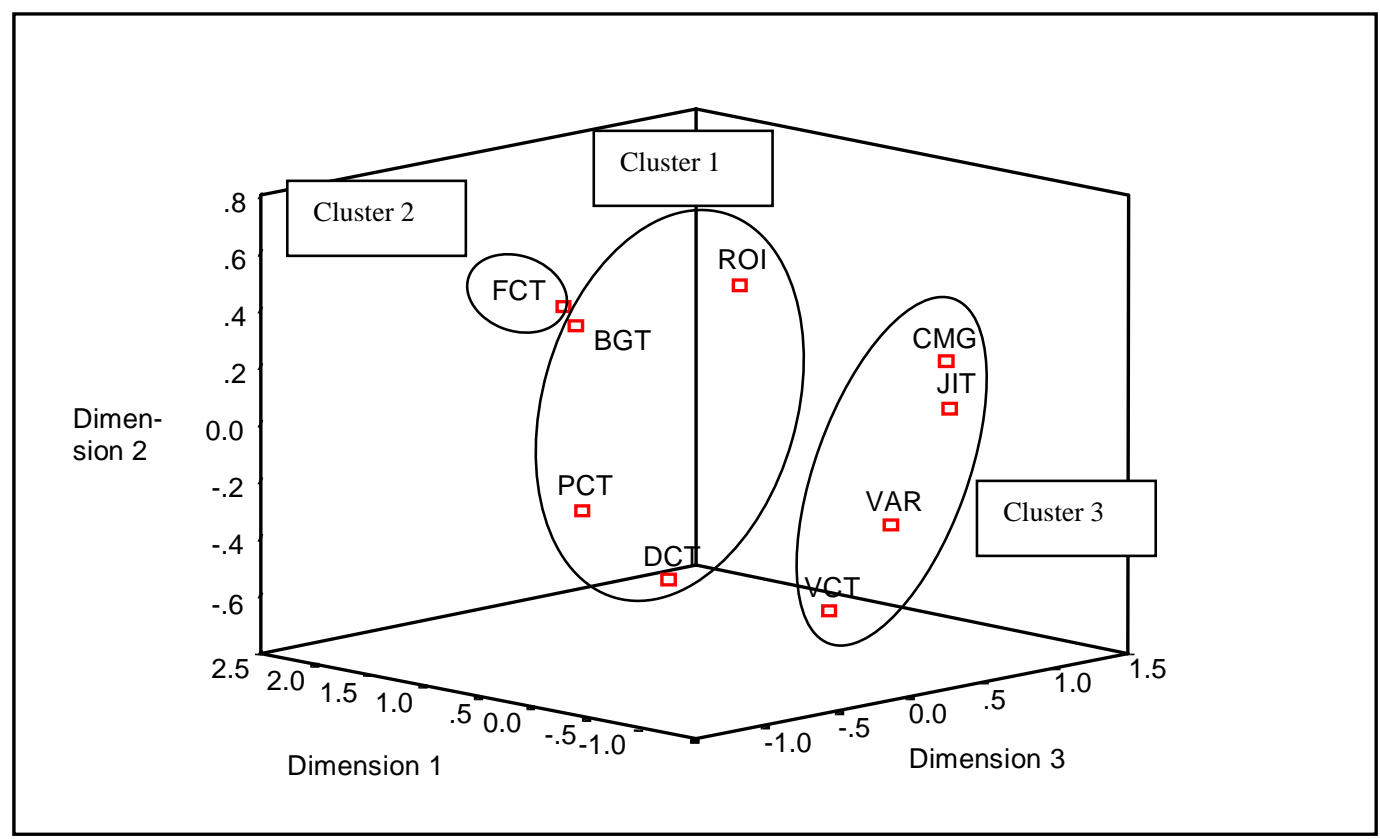

2. Two-dimensional map

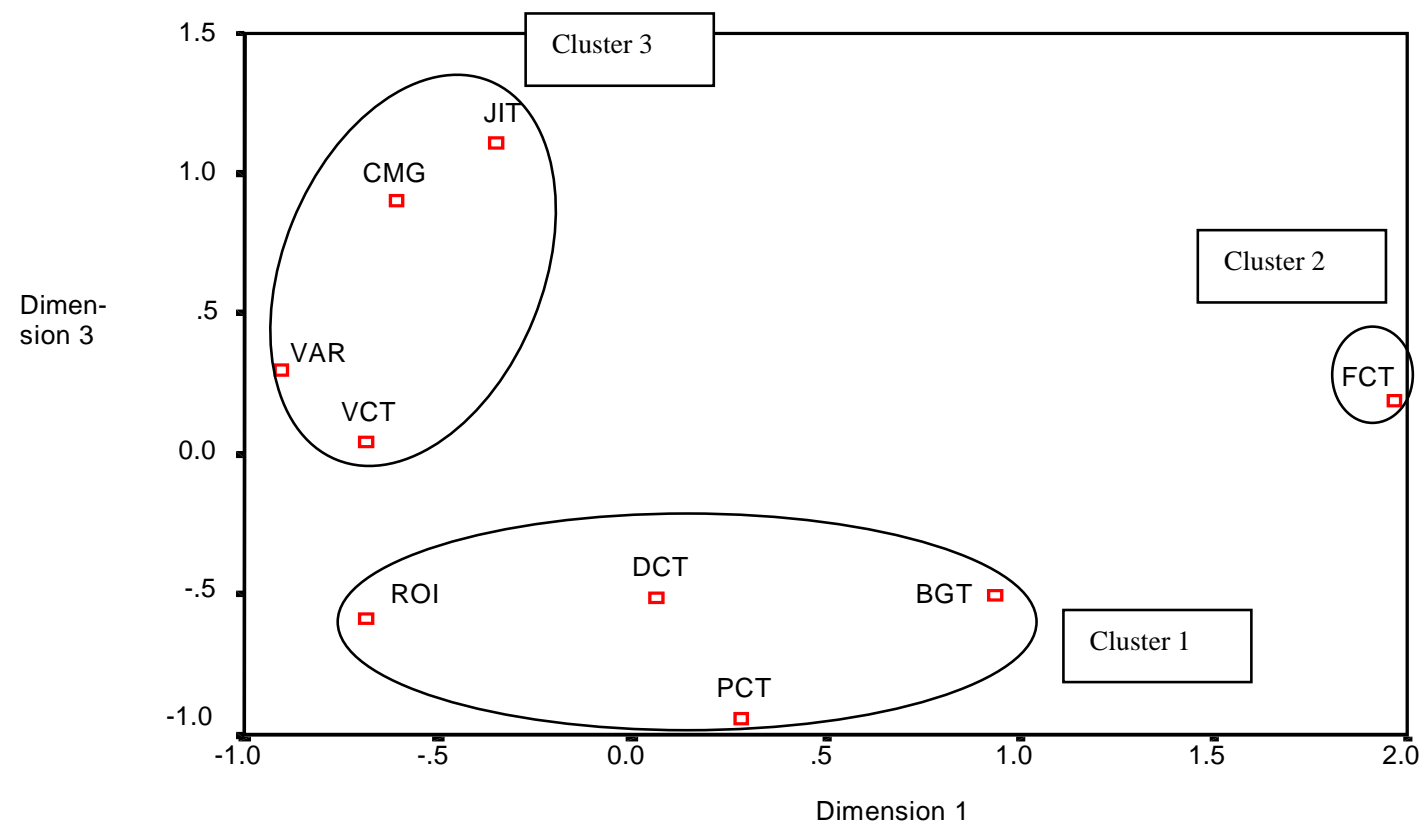

Figure 1 Perceptual Maps for Organizational Culture (continued) 
The above findings indicate that organizational culture is associated with differential perceptions of managerial accounting terms. In other words, organizational members of different organizational culture perceive the same managerial accounting terms differently.

\section{Occupational Culture and Perception of Managerial Accounting Terms}

INDSCAL was also performed on the two distance matrices for management accountants and non-financial managers. As shown in Table 3, the Stress index is 0.0882 and the R-square is $95.79 \%$, indicating a good fitting model. Table 3 also shows the coordinates of the three-dimensional common perceptual map of the perceptions of the nine managerial accounting terms for management accountants and non-financial managers. As before, the individual group perceptual maps can be derived by multiplying the common perceptual map coordinates by the square roots of the respective weights for the two occupational groups.

To analyze the INDSCAL results further, the perceptual maps for management accountants and non-financial managers are plotted in Figure 2. The results of cluster analysis are also incorporated in Figure 2 by drawing the boundaries of the different clusters of similarly perceived terms.

An obvious difference between the perceptions of management accountants and non-financial managers is that the former perceive the nine managerial accounting terms with only two dimensions whereas the latter do so with three dimensions. This finding is consistent with the explanation that management accountants, given their background (e.g., education and experience in managerial accounting), are better able to perceive managerial accounting terms more concisely and precisely. Hence, they need only two dimensions to adequately perceive the terms.

Another difference that can be noted from Figure 2 is the relative position (and cluster membership) of the terms as perceived by management accountants and nonfinancial managers. In particular, the management accountants perceive return on investment and contribution margin to be a separate cluster. On the other hand, nonfinancial managers perceive direct cost and product cost to be a separate cluster. One possible explanation for the differential perceptions is the different roles played by the terms for each of the two occupational groups; this, in turn, leads to differences in the perceived meaning of as well as the attitude towards the terms.

Management accountants are providers of accounting information and they may perceive the nature of return on investment and contribution margin as relating to decision making; the other managerial accounting terms (i.e. those in clusters 1 and 2) 
relate primarily to production. In contrast, non-financial managers not only make use of accounting information (e.g., in production), they are also evaluated on the basis of accounting information. Hence, return on investment and contribution margin are likely similar to variance, variable cost and just-in-time, which together may be seen as a package of control and evaluation devices. This explanation is consistent with viewing management accountants as part of the "engineers" culture in the organization and non-financial managers as part of the "operators" culture.

Table 3 INDSCAL Results for Occupational Culture

\begin{tabular}{|c|c|c|c|}
\hline \multicolumn{4}{|l|}{ A. Common perceptual map } \\
\hline Managerial accounting term & Dimension 1 & Dimension2 & Dimension 3 \\
\hline Budget (BGT) & 1.03 & 0.15 & -1.48 \\
\hline Product cost (PCT) & -0.01 & 0.57 & -1.34 \\
\hline Fixed cost (FCT) & 2.26 & 0.90 & -0.92 \\
\hline Direct cost (DCT) & -0.50 & 0.97 & -0.40 \\
\hline Return on investment (ROI) & -0.14 & -2.16 & 0.57 \\
\hline Variance (VAR) & -1.03 & 0.26 & 1.15 \\
\hline Contribution margin (CMG) & -0.23 & -1.30 & 1.32 \\
\hline Just-in-time (JIT) & -0.21 & -0.10 & 0.45 \\
\hline Variable cost (VCT) & -1.18 & 0.70 & 0.65 \\
\hline \multicolumn{4}{|c|}{ Stress $=0.0882 ; \quad$ R-square $=0.9579$} \\
\hline \multicolumn{4}{|c|}{ B. Individual group perceptual maps } \\
\hline \multirow[t]{2}{*}{ Organizational culture } & & Weights: & \\
\hline & Dimension 1 & Dimension 2 & Dimension 3 \\
\hline Management accountants & 0.91 & 0.35 & 0.00 \\
\hline Non-financial managers & 0.71 & 0.38 & 0.56 \\
\hline \multicolumn{4}{|c|}{ C. Cluster membership } \\
\hline \multicolumn{2}{|c|}{ Management accountant } & \multicolumn{2}{|c|}{ Management accountant } \\
\hline Cluster1 & Cluster3 & Cluster1 & Cluster3 \\
\hline BGT & CMG & DCT & CMG \\
\hline \multirow[t]{4}{*}{ FCT } & ROI & PCT & ROI \\
\hline & & & VCT \\
\hline & & & VAR \\
\hline & & & JIT \\
\hline
\end{tabular}




\section{A. Management accountants}

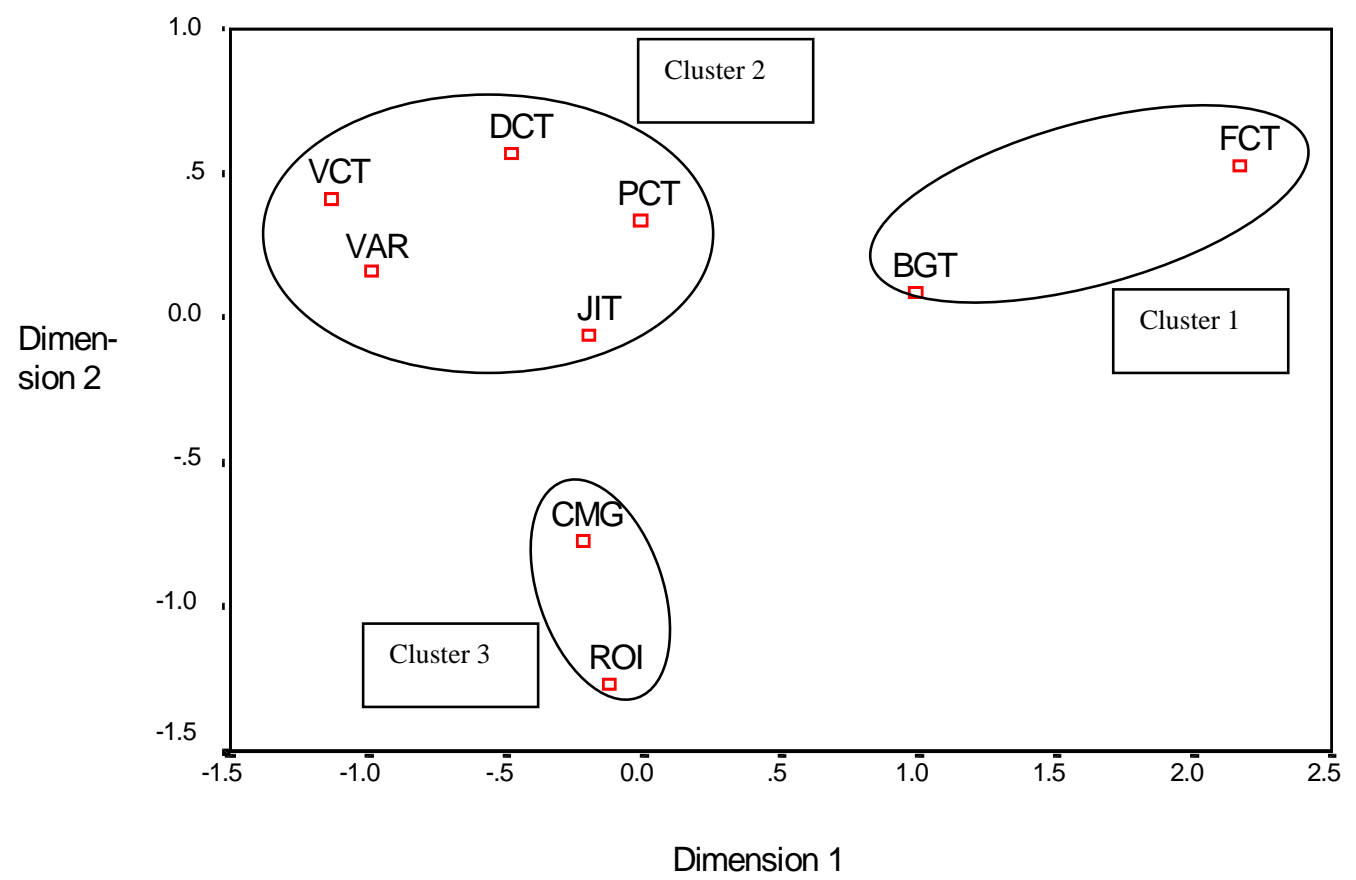

B. Non-financial managers

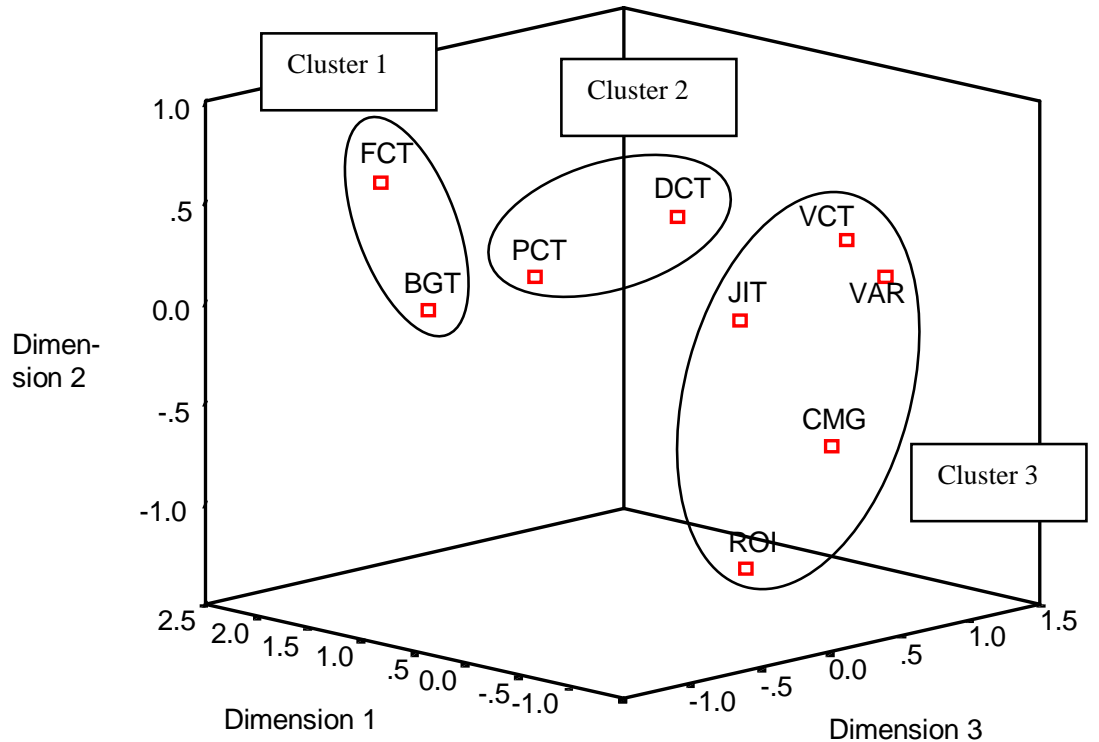

Figure 2 Perceptual Maps for Occupational Culture 
The above findings indicate that occupational culture is associated with differential perceptions of managerial accounting terms. As expected, it is found that management accountants and non-financial managers, as two occupational groups with different culture, do perceive managerial accounting terms differently. More narrowly, as suggested by prior research, management accountants and non-financial managers may also possess different professional culture (see, for example, Granlund and Lukka (1998) and Jackall (1988)).

\section{Implications}

Organizational culture and occupational culture are powerful forces that drive organizations and their members. They have been found to significantly affect technological innovation and its implementation (von Meier, 1999), organizational improvement and learning (Ahmed et al., 1999), total quality management (Dellana and Hauser, 1999), accounting systems and their implementation (Malmi, 1997), success of mergers and takeovers (Yaakov, 1996), the welfare of employees and managers (Yeung, 1999), profitability (Bliss, 1999) and the organization itself (Holmes and Marsden, 1996).

This study found that the perception of managerial accounting terms is also associated with organizational and occupational culture. That is, the same managerial accounting terms may not be perceived similarly by members of different organizational cultures and/or different occupational cultures. The former affects the effectiveness of inter-organizational accounting communication (e.g., between parent companies and their subsidiaries) and the latter affects the effectiveness of intraorganizational accounting communication (e.g., between members of different functional groups within the same organization). This finding is not unexpected given that the perception of messages is dependent on the filter used in the encoding and decoding process, and that the filter used is dependent on the sender's/receiver's background. Culture captures much of the background of message senders and receivers.

Overall, the study indicates the importance of understanding the effects of different organizational and occupational cultures. This study examines the issues in the context of accounting communication. On a more pragmatic level, Lewis (1985) suggested that to enhance effective communication, accountants should insist on getting feedback from the receiver (of the accounting information) to ensure that no miscommunication has occurred, be receiver-oriented (e.g., by considering the background and experience of the receiver during communication), and use several 
communication channels (e.g., written reports as well as oral communications) to alleviate the problem of ineffective filtering. In addition, Hussey (1981) suggested that accounting information should be made as user-friendly as possible to the recipients (e.g., with respect to format). Along the same line, Murray (1994) stressed the importance of format and presentation and a proper balance of substance and form. Further, Madonik (1994/95) advised management accountants to understand the models of the world and structures of the language of the people they communicate with in order to engage in productive communication.

\section{CONCLUSION}

Based on a sample of 64 management accountants and 68 non-financial managers from ten organizations and the INDSCAL and cluster analysis results, the study concludes that different organizational and occupational cultures are associated with differential perceptions of managerial accounting terms. This finding has implications on the effectiveness of accounting communication. More importantly, it shows the importance of understanding the effects of organizational and occupational cultures. Prior research has found them to be powerful forces driving organizations and their members.

In the concluding section, it is appropriate to highlight the limitations of the study and suggest directions for future research.

\section{Limitations of Study}

Being an exploratory study, it does not attempt to test formal research hypotheses or find causal relationships. Instead of using p-values and statistical significance, the study relies on "softer" interpretation of the results to gain insight into the research questions. Despite this, the findings from this exploratory study can still be useful (e.g., in helping to understand the area of interest or to generate possible research hypotheses).

Given the self-report instrument used, the usual limitations with survey questionnaire research apply. However, response bias is not expected to be a problem as the questions are generally neutral and anonymity of responses is assured. Nonresponse bias may exist in that the organizations that did not agree to participate in the study may be substantially different from those that did. Or that the organizational members who responded may be substantially different from those who did not. External validity may also be questioned with respect to the representativeness of the sample. 


\section{Directions for Future Research}

Future research can attempt to link differences in organizational and occupational cultures to differences in perception to better understand the effects of organizational and occupational cultures. In particular, future research can test specific research hypotheses based on the exploratory findings reported in the study. More generally, it may be useful to study the effects of organizational and occupational cultures on organizational processes other than the accounting communication process.

Finally, it is noted that encoding and decoding messages is only a part (though a crucial one) in the accounting communication process. In particular, accounting communication also involves the skills of accountants in reporting on facts about economic events and effects on behalf of the receivers (e.g., shareholders and managers) without prejudging any particular actions of the latter (Lee, 1982). Thus, it calls into question the credibility of both the processors of accounting information (i.e. the accountants) and the process of information generation (i.e. the accounting process). Future research can investigate how these impact on effective accounting communication.

Despite the limitations highlighted above, it is hoped that this study can make a contribution to the literature on organizational and occupation cultures and accounting communication.

\section{ACKNOWLEDGMENT}

We are grateful to the Committee on Academic Relations of the Institute of Management Accountants for providing financial support for this study through a dissertation research grant.

\section{REFERENCES}

Adelberg, A. H., \& Farrelly, G. E. (1989). Measuring the Meaning of Financial Statement Terminology: A Psycholinguistics Approach. Accounting and Finance, 29, 33-61.

Ahmed, P. K., Loh, A. Y. E., \& Zairi, M. (1999). Cultures for Continuous Improvement and Learning. Total Quality Management, 10, 426-434.

Bayou, M. E. (1993). Standardization Issues in Management Accounting Communication. Accounting, Auditing \& Accountability Journal, 6, 32-51.

Belkaoui, A. (1980). The Interprofessional Linguistic Communication of Accounting Concepts: An Experiment in Sociolinguistics. Journal of Accounting Research, 18, 362-374.

Bliss, W. G. (1999). Why is Corporate Culture Important? Workforce, 78, 8-9. 
Bloor, G., \& Dawson, P. (1994). Understanding Professional Culture in Organizational Context. Organization Studies, 15, 275-292.

Carroll, J. D., \& Chang, J. J. (1970). An Analysis of Individual Differences in Multidimensional Scaling via an N-way Generalization of 'Eckart-Young' Decomposition. Psychometrica, 35, 283-319.

Chatman, J. A., \& Jehn, K. A. (1988). Assessing the Relationship between Industry Characteristics and Organizational Culture. Academy of Management Journal, 37, 522-542.

Cooke, R. A., \& Lafferty, J. C. (1984 and 1987). Organizational Culture Inventory. Plymouth: Human Synergistics.

Cooke, R. A., \& Rousseau, D. M. (1988). Behavioral Norms and Expectations: A Quantitative Approach to the Assessment of Organizational Culture. Group \& Organizational Studies, 13, 245-273.

Dellana, S. A., \& Hauser, R. (1999). Toward Defining the Quality Culture. Engineering Management Journal, 11, 11-20.

Dessler, G. (1984). Human Behavior: Improving Performance at Work. Reston: Reston Publishing Company.

Gibson, J. L., Ivancevich, J. M., \& Donnelly, J. H. (Jr.) (1994). Organizations: Behavior, Structure, Processes. Plano: Business Publications.

Goldberg, G. M. (1965). An Inquiry into the Nature of Accounting. New York: Arno Press.

Granlund, M., \& Lukka, K. (1998). Towards Increasing Business Orientation: Finnish Management Accountants In a Changing Cultural Context. Management Accounting Research, 9, 185-211.

Hansen, C. D. (1995). Occupational Cultures: Whose Frame Are We Using? The Journal for Quality and Participation, 18, 60-67.

Hansen, C. D., \& Kahnweiler, W. M. (1997). Executive Managers: Cultural Expectations Through Stories About Work. Journal of Applied Management Studies, 6, 117-138.

Haried, A. (1972). The Semantic Dimensions of Financial Statements. Journal of Accounting Research, 12, 376-391.

Haried, A. (1973). Measurement of Meaning in Financial Reports. Journal of Accounting Research, 13, 117-145.

Hofstede, G. (1991). Cultures and Organizations: Software of the Mind. New York: McGraw-Hill. 
Hofstede, G. (1998a). Identifying Organizational Subcultures: An Empirical Approach. The Journal of Management Studies, 35, 1-12.

Hofstede, G. (1998b). Attitudes, Values and Organizational Culture: Disentangling the Concepts. Organization Studies, 19, 477-492.

Hofstede, G., Neuijen, B., Ohayv, D., \& Sanders, G. (1990). Measuring Organizational Cultures: A Qualitative and Quantitative Study Across Twenty Cases. Administrative Science Quarterly, 35, 286-316.

Holmes, S., \& Marsden, S. (1996). An Exploration of the Espoused Organizational Cultures of Public Accounting Firms. Accounting Horizons, 10, $26-53$.

Houghton, K. A. (1987). The Development of Meaning in Accounting: An Intertemporal Study. Accounting and Finance, 27, 25-40.

Houghton, K. A. (1988). The Measurement of Meaning in Accounting: A Critical Analysis of the Principal Evidence. Accounting, Organizations and Society, 13, 263-280.

Howell, R. A., \& Soucy, S. R. (1987). The New Manufacturing Environment: Major Trends for Management Accounting. Management Accounting, 65, 21-27.

Hussey, R. (1981). Getting the Financial Message Across to Employees. Accountancy, 92, 109-112.

Jackall, R. (1988). Moral Mazes: The World of Corporate Managers. New York: Oxford University Press.

Johnson, S. D., Killough, L. N., \& Schulman, R. (1999). The Impact of Organizational and Professional Culture on the Effectiveness of Management Accounting Communication. Advances in Management Accounting, 8, 71-93.

Kilman, R. H., \& Saxton, M. J. (1983). The Kilman-Saxton Culture-gap Survey. Pittsburgh: Organizational Design Consultants.

Lee, T. A. (1982). Chambers and Accounting Communication. Abacus, 18, 152-165.

Lewis, R. D. (1996). When Cultures Collide. London: Nicholas Brealey Publishing.

Lewis, T. D. (1985). Did You Say What You Said or ... Did You Say What I Think You Said? Management Accounting, 67, 40-45.

Low, C. K., \& Koh, H. C. (1997). Concepts Associated with the 'True and Fair View': Evidence from Singapore. Accounting and Business Research, 27, 195-202.

Madonik, B. (1994/1995). The Structure of Irresistible Communication. CMA, 68, 6-7. Malmi, T. (1997). Towards Explaining Activity-based Costing Failure: Accounting and Control in a Decentralized Organization. Management Accounting Research, $8,459-480$. 
Monti-Belkaoui, J., \& Belkaoui, A. (1983). Bilingualism and the Perception of Professional Concepts. Journal of Psycholinguistic Research, 12, 111-127.

Murray, P. (1994). Mastering Management Reporting. Australian Accounting, 64, 2329.

Ott, J. S. (1989). The Organizational Culture Perspective. Chicago: The Dorsey Press. Parker, L. D., Ferris, K. R. \& Otley, D. T. (1989). Accounting for the Human Factor. New York: Prentice-Hall.

Poon, C. C., \& Koh, H. C. (1995). Budget Usefulness and its Determinants: An Analysis of Hong Kong Companies. Annual Congress of the European Accounting Association. Birmingham: United Kingdom.

Pratt, J., Mohrweis, L. C., \& Beaulieu, P. (1992). The Interaction between National and Organizational Culture in Accounting Firms: An Extension. Accounting, Organizations and Society, 18, 621-628.

Schein, E. H. (1996). Culture: The Missing Concept in Organization Studies. Administrative Science Quarterly, 41, 229-240.

Sherblom, J. C. (1998). Transforming Business Communication by Building on Forman's Translation Metaphor. The Journal of Business Communication, 35, 74-86.

Smircich, L. (1983). Organizations as Shared Meaning. in L. R. Pondy, P. Frost, G. Morgan \& T. Dandridge (eds.), Organizational Symbolism. Greenwich: JAI Press. von Meier, A. (1999). Occupational Cultures as a Challenge to Technological Innovation. IEEE Transactions on Engineering Management, 46, 101-114.

Xenikou, A. \& Furnham, A. (1996). A Correlational and Factor Analytic Study of Four Questionnaire Measures of Organizational Culture. Human Relations, 49, 349-371.

Yaakov, W. (1996). Corporate Cultural Fit and Performance in Mergers and Acquisitions. Human Relations, 49, 1181-1199.

Yeung, R. (1999). In at the Deep End. Accountancy, 123, 44. 
